\title{
PEMANFAATAN SUMBER AIR PEGUNUNGAN UNTUK MENGANTISIPASI KEKERINGAN PADA MUSIM KEMARAU UNTUK TANAMAN KUBIS \\ (To Exploit Mountain Water Resource for Anticipation Drought at Dry Season for Cabbage)
}

\author{
Meinarti Norma S dan Sodiq Jauhari \\ Balai Pengkajian Teknologi Pertanian Jawa Tengah
}

E-mail: smeinartinorma@yahoo.com

\begin{abstract}
Operational step for dry season anticipation among to take schedule in plant pattern at location which often affected El Nino, to evaluate rain characteristic, to evaluaete irrigation availability, to prepare irrigation infrastructure and exploit alternative water resources. Beginning step for to got time and plant pattern with climate data is CWB-Eto program simulation. In this activity, data is taked from climate data at Canggal, Temanggung 2006, cabbage agronomy data and content water data. The result of climate data observation and CWB-Eto program simulation show the rain with $100 \mathrm{~mm}$ occurred at January - April and November - December, while the $20 \%$ lost yield occurred. When farmer plants cabbage at January - Mei and September October. For anticipation drought, micro irrigation and micro climate modification will decrease lost yield. The farmer when he will plant cabbage at dry season must make micro climate among mulc and irrigation with three day one. When we compare between the result research FAO and at Canggal, so cabbage which at Canggal was in good condition. Cabbage production at Canggal was $1,1 \mathrm{~kg} / \mathrm{plant}$ and cabbage production at the result FAO is between $1-1.7 \mathrm{~kg}$ / plant.
\end{abstract}

Key word : anticipation, cabbage, drought, dry season, mountain water resource,

\section{PENDAHULUAN}

Antisipasi anomali iklim menurut Fagi et al. (2002) bertujuan : 1) menyiapkan upaya dan pemanfaatan teknologi tepat guna, 2) mengupayakan penanggulangan dan penyelamatan tanaman dari kemungkinan deraan kekeringan atau banjir dan 3) mengurangi dampak El-Nino terhadap penurunan produksi tanaman. Program aksi antisipasi dan penanggulangan harus dipilah menurut waktu yaitu sebelum, selama dan sesudah terjadi anomali iklim.

Langkah operasional dalam mengantisipasi kekeringan menurut Fagi et al. (2002) adalah : 1) Membuat rencana tanam dan pola tanam pada lokasi yang sering dilanda El-Nino, mengevaluasi karakteristik curah hujan serta pola ketersediaan air irigasi, 2) menyipakan benih varietas yang relatif toleran kekeringan berumur sangat genjah atau tanaman alternatif yang lebih toleran kering, 3) menyiapkan infrastruktur irigasi, 4) memanfaatkan sumber daya air alternatif dan menyusun serta menyiapkan program aksi pada musim hujan setelah kekeringan.

Penyerahan naskah

: 19 November 2008

Diterima untuk diterbitkan

10 Desember 2008 
Pemanfaatan sumber air pegunungan

Adanya kabar perubuhan iklim yang mempengaruhi jumlah air pada setiap musim juga mempengaruhi teknik pemanfaatan air pada budi daya sayuran dataran tinggi. Di dalam budi daya pertanian dataran tinggi, petani biasa tergantung pada air hujan untuk menyirami tanamannya. Namun beberapa tahun terakhir, petani memanfaatkan pengetahuannya tentang penampungan air yang bermula dari air limpasan permukaan. Menjadikan lahan kering yang semula dianggap sumberdaya marjinal atau suboptimal dengan salah satu tindakan pengelolaan air yang baik akan menempatkan lahan kering menjadi lahan strategis pertanian di masa mendatang. Dan sudah saatnya sistem hidrologi di lahan kering mendapat prioritas perhatian di masa mendatang.

Menurut Arsyad S. (2000) irigasi adalah pemberian air kepada tanah untuk memenuhi kebutuhan air bagi pertumbuhan tanaman. Pekerjaan irigasi meliputi penampungan dan pengambilan air dari sumbernya, pengaliran air melalui saluran atau pipa ke tanah dan pembuangan air yang berlebih. Tujuan irigasi adalah memberikan tambahan air terhadap air hujan dan memberikan air kepada tanaman dalam jumlah yang cukup dan pada waktu diperlukan. Selain untuk memenuhi kebutuhan air tanaman, air irigasi mempunyai kegunaan lain seperti : mempermudah pengolahan tanah, mengatur suhu tanah dan iklim mikro, membersihkan tanah dari kadar garam atau asam terlalu tinggi, membersihkan kotoran-kotoran dari selokan (sanitasi), dan menggenangi tanah untuk memberantas tumbuhan pengganggu dan hama penyakit

Cara pemberian air irigasi dapat di bagi dalam empat golongan : 1) Pemberian air pada permukaan tanah yang dapat dilakukan berupa a) penggenangan bebas, penggenangan tepi, penggenangan galengan, b) pemberian air dalam selokan-selokan, c) pemberian air di antara baris tanaman, d) pemberian air pada bokoran tanaman, 2) Pemberian air di bawah permukaan atau di dalam profil tanah. Air diberikan melalui semacam pipa-pipa saluran yang dibenamkan di bawah permukaan tanah, 3) Pemberian air dengan cara penyiraman dapat berupa penyiraman bergoyang dan penyiraman berputar dan 4) Pemberian air dengan mengalirkan air melalui lubang-lubang kecil yang dibuat sepanjang pipa langsung ke tanaman dengan laju aliran rendah (irigasi tetes). Secara keseluruhan efisiensi penggunaan air dapat ditingkatkan melalui, a) mengurangi tinggi penggenangan atau banyaknya air yang diberikan, b) mengurangi kebocoran-kebocoran saluran irigasi dan galengan, c) peningkatan produktivitas dengan penggunaan bibit dan sarana yang lebih baik, d) pergiliran pemberian air dan e) pemberian air secara terputus.

\section{BAHAN DAN METODE}

Introduksi teknologi dengan mempertimbangkan pemanfaatan data iklim belum banyak dikenal dilapangan khususnya petani. Ada dua pemanfaatan data iklim untuk introduksi 
teknologi yaitu untuk program simulasi sehingga mendapatkan pola tanam dan kehilangan hasil pada beberapa komoditas dan pemanfaatan hasil simulasi untuk menentukan introduksi irigasi yang efisien air yaitu irigasi tetes. Data iklim sebagai data primer yang dipakai dalam menentukan waktu tanam kubis adalah data AWS Kertek, Wonosobo dan AWLR tahun 2006. Data agronomi kubis diambil dari lapang dari pertanaman Desa Canggal, Kledung, Temanggung. Sedangkan data kadar air tanah merupakan data sekunder hasil penelitian IPB. Ketiga komponen data merupakan input pada program CWB-ETO yang hasil akhir merupakan nilai kehilangan hasil. Hasil penelitian Allen et al. (1998) dan CIRAD dalam Estiningtyas (2002) menyatakan bahwa kehilangan hasil yang masih bisa diterima adalah $20 \%$. Lebih dari nilai tersebut tidak dianjurkan karena kerugian yang akan ditimbulkan cukup besar. Selanjutnya dihitung nisbah ETR/ETM dan persentase kehilangan hasil pada setiap fase tanaman dan setiap tanggal tanam. Waktu tanam ditentukan dengan memperhitungkan nisbah ETR/ETM > 0,8 dan persentase kehilangan hasil $<20 \%$ terutama pada fase kritis tanaman.

Untuk menimalkan kehilangan menjelang musim kemarau, biasanya petani dataran tinggi menampung air hujan pada kolam plastik. Pemilihan teknik penampungan air tergantung pada berbagai faktor, seperti iklim, sifat tanah, ketersediaan bebatuan dan tenaga, pengalaman petani tentang penampungan sebelumnya, tingkat organisasi sosial dan faktor-faktor sosial ekonomi lainnya. Meskipun penampungan air sebagai suatu teknik peningkatan sumber daya sangat penting di daerah agak kering tetapi juga dapat diterapkan di daerah sedang misalnya untuk mendapatkan keuntungan maksimum dari hujan pertama untuk produksi semaian awal atau tanaman awal. Di daerah Canggal, Temanggung air yang telah ditampung, dikocorkan ke setiap tanaman kubis pada akhir musim penghujan. Pemanfaatan saluran pembuangan air di bawah bibir teras merupakan teknik penampungan air yang cukup efektif bagi petani dengan lahan sempit (Gambar 1).

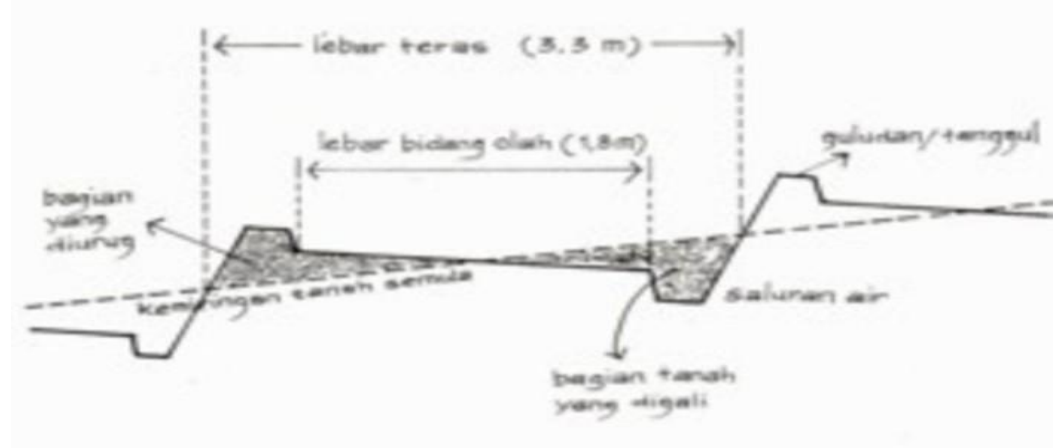

Gambar 1. Pembuatan teras bangku 


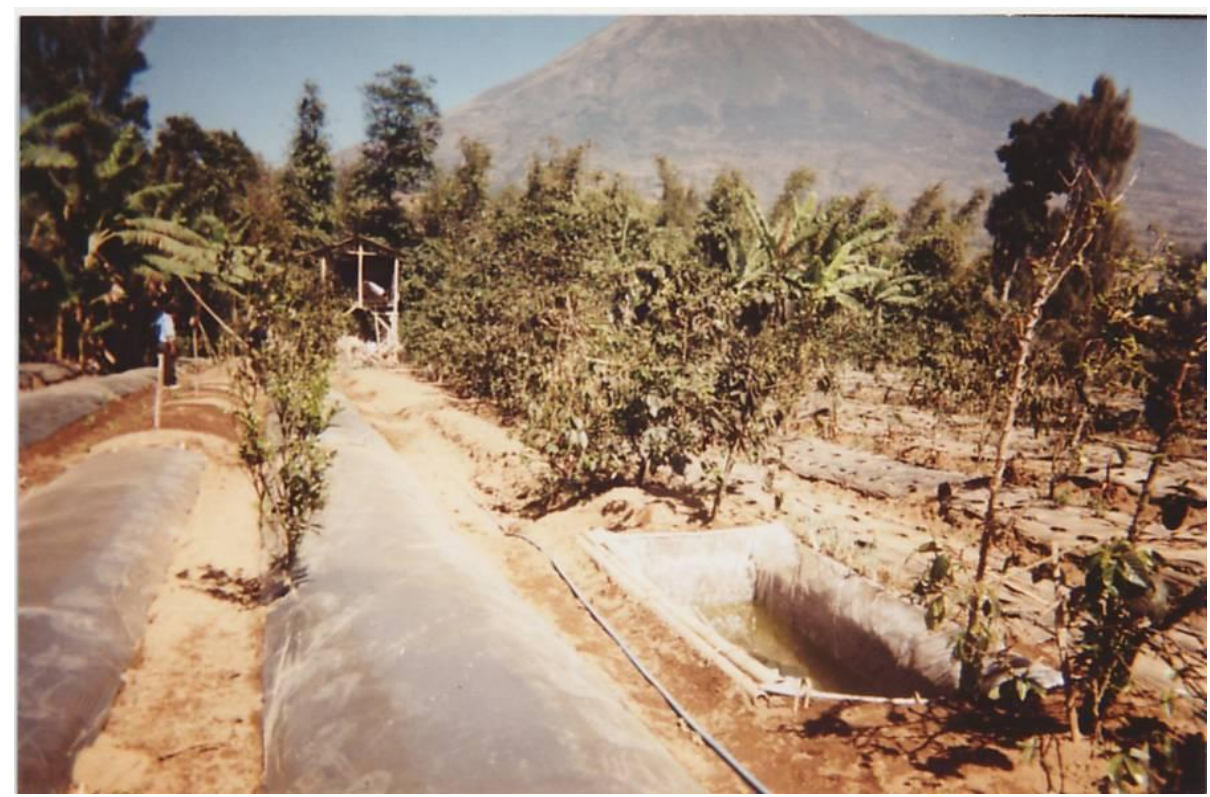

Gambar 2. Kolam penampungan plastik yang digunakan untuk menyirami tanaman hortikultura, pemupukan maupun penyemprotan pestisida di Desa Canggal, Kecamatan Kledung, Kabupaten Temanggung

Untuk mendapatkan informasi waktu panen dan produksi tanaman palawija dan hortikultura di sekitar lokasi AWS ada beberapa tahapan :

a) Pengambilan data (umur tanaman berbagai fase fenologi, tinggi tanaman maksimum dan panjang akar maksimum) tanaman pangan dan hortikultura sebagai input dalam program CWB-ETO. Pengambilan data agronomi ini dilaksanakan pada awal tanam sampai panen di lokasi lahan kering dataran tinggi Desa Canggal, Kecamatan Kledung, Temanggung. Ada 2 (dua) petani yang menjadi kooperator yaitu Muhyasin dan Sudirjo. Lahan petani yang dipakai sekitar $1000 \mathrm{~m}^{2}$. Waktu pelaksanaan dari September - Desember 2006. Perlakuan yang dpakai adalah a) penyiraman 3 hari sekali dengan volume yang sama (500 $\mathrm{ml})$, b) penyiraman setiap hari $(500 \mathrm{ml})$, c) tanpa mulsa dan d) pakai mulsa. Setiap lokasi lahan petani terdapat 2 kolam plastik penampung air yang berukuran panjang 4-5 m, lebar $1 \mathrm{~m}$ dan kedalaman 0.7-1 m. Kolam plastik dibangun di bawah permukaan tanah. Air yang ditampung berasal dari sumber mata air yang dihubungkan dengan slang plastik (Gambar 2).

b) Data agronomi, yang diamati antara lain tinggi tanaman, kedalaman akar, waktu keluar daun pertama, waktu pemindahan bibit, waktu keluar bunga, waktu tinggi tanaman mencapai maksimum dan kedalaman akar maksimum, waktu panen pertama dan terakhir, produksi setiap tanaman (diambil 3 tanaman setiap perlakuan),produksi keseluruhan luas lahan dan 
waktu tanam. Data primer ini masuk sebagai input dalam program simulasi CWB-ETO disamping data iklim (curah hujan dan evapotranspirasi) dan data sekunder kadar air tanah Temanggung (Hasil pengamatan Tim Institut Pertanian Bogor).

\section{HASIL DAN PEMBAHASAN}

Desa Canggal, Kledung, Temanggung terletak di antara Gunung Sundoro dan Sumbing sehingga dapat dikatakan dari segi iklim daerah ini mempunyai iklim spesifik (terjadi angin gunung dan merupakan daerah bayangan hujan). Jumlah hujan bulanan cukup di atas $100 \mathrm{~mm}$ yang terjadi pada bulan Januari sampai April dan pada bulan Desember. Daerah ini merupakan lahan kering yang sangat terbatas sumber airnya. Dari pengamatan data iklim otomatis di stasiun Kretek dan data curah hujan dari stasiun otomatis AWLR Pagerejo. Data curah hujan dan evapotranspirasi yang terekam dari kedua stasiun yang terletak di Kabupaten Wonosobo (Gambar 3).

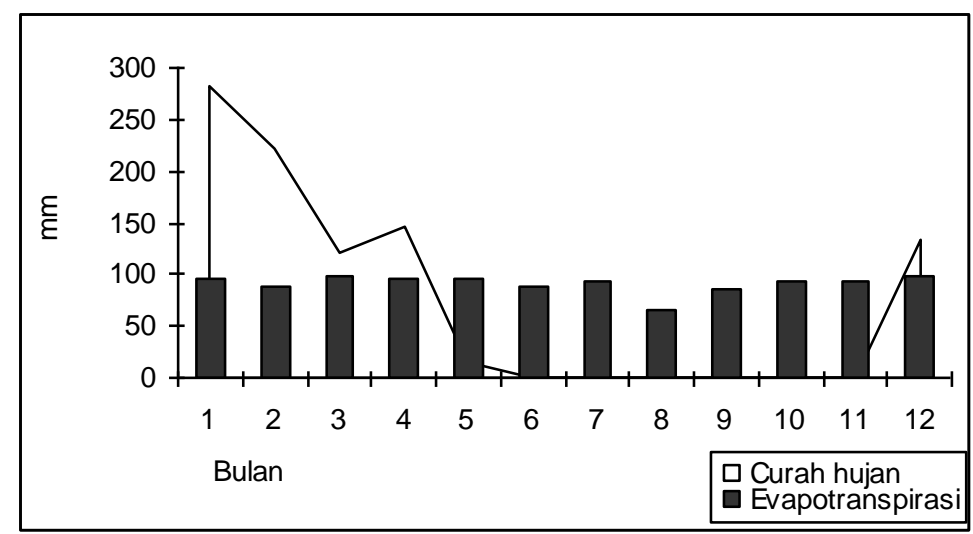

Gambar 3. Grafik jumlah curah hujan dan evapotranspirasi bulanan di Kretek Kabupaten Wonosobo 2006

Jumlah air yang diuapkan setiap bulan cenderung sama yaitu sekitar $100 \mathrm{~mm}$ sedangkan jumlah curah hujan mulai berkurang setelah bulan April sampai bulan Nopember. Untuk melihat hasil introduksi irigasi, maka penanaman dilakukan pada musim kemarau yaitu antara bulan April sampai bulan Oktober dengan memanfaatkan air pegunungan yang ditampung dalam kolam plastic (Gambar 3).

Prediksi hasil simulasi dengan menggunakan program CWB - ETo selain dijadikan sebagai penentuan waktu tanam dapat dijadikan untuk penentuan waktu tanam pada tahuntahun ekstrim, prediksi produksi pada tahun ekstrim dan penentuan waktu aplikasi irigasi alternative dengan menggunakan jaringan irigasi makro (seperti waduk atau embung) atau 
menggunakan irigasi mikro seperti irigasi penampungan skala ekonomi (jaringan irigasi tetes baik itu manual maupun teknis). Hasil analisis Setiapermas et al (2008) dengan menggunakan program CWB-ETo pada tanaman cabai merah didapat bahwa kehilangan hasil di lokasi Canggal, Kledung, Temanggung bahwa penyiraman setiap hari $(500 \mathrm{ml})$ lebih baik dibandingkan dengan penyiraman tiga hari sekali $(500 \mathrm{ml})$. Bila tidak ada penyiraman pada waktu pertanaman September - Desember 2006 kehilangan hasil dapat mencapai $70 \%$ sedangkan bila dengan penyiraman setiap hari kehilangan hasil dapat mencapai $60 \%$ dan kehilangan hasil pada pertanaman dengan penyiraman tiga hari sekali mencapai $75 \%$. Dengan simulasi ini pelaku pertanian dapat memperkirakan berapa liter tanaman (yang dikonversikan ke mm curah hujan) untuk disiramkan ke akar tanaman.

Hasil simulasi program CWB-ETO pada beberapa sayuran untuk daerah Canggal (Gambar 4). Kehilangan hasil utuk tanaman kubis dengan hanya mengandalkan curah hujan bila penanaman dilakukan dari bulan Januari sampai pertengahan bulan Mei dan dari pertengahan bulan September sampai bulan Oktober menghasilkan kehilangan produksi di bawah $20 \%$, artinya penanaman kubis pada waktu tersebut produksi diperkirakan $80 \%-100$ $\%$ dari produksi maksimum. Sedangkan bila dilakukan penanaman pada pertengahan bulan Mei sampai pertengahan bulan September kehilangan produksi lebih dari $20 \%$.

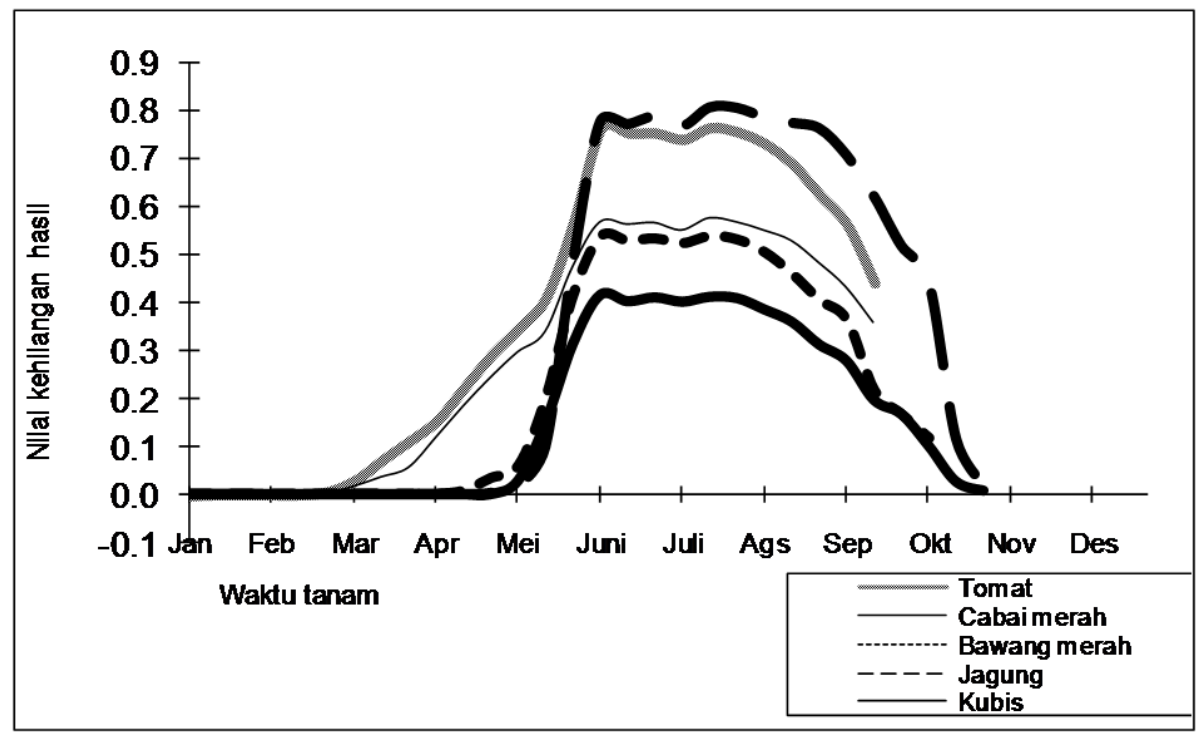

Gambar 4. Grafik nilai kehilangan hasil sayuran dan pangan pada tahun 2006 di lokasi AWS Kretek

Penanaman kubis di Canggal dilakukan pada pertengahan bulan Sepetember yaitu 18 September 2006 sampai panen 29 November 2006. Diperkirakan bila penanaman pada 
tanggal 18 September, kehilangan produksi kubis mencapai $20 \%$. Karena ada introduksi irigasi (penyiraman) maka diharapkan kehilangan produksi tidak mencapai $20 \%$. Dengan dilakukannya penyiraman manual, pemakaian air untuk setiap tanaman kubis dengan penyiraman setiap hari $(500 \mathrm{ml})$ adalah 31.5 liter, sedangakan dengan penyiraman selang 3 hari adalah 11 liter.

Hasil produksi dengan perlakuan mulsa dan selang penyiraman pada pertanaman Pak Muhyasin, kubis tidak dapat dipanen karena terserang ulat, sedangkan pada pertanaman pak Sudirjo adalah sebagai berikut :

Tabel 1. Berat kubis per tanaman pada lahan Pak Sudirjo

\begin{tabular}{lll}
\hline Perlakuan penyiraman & \multicolumn{2}{c}{ Berat kubis per tanaman $(\mathrm{Kg})$} \\
\cline { 2 - 3 } & Memakai mulsa & Tidak memakai mulsa \\
\hline Penyiraman setiap hari & 1.1 & 0.9 \\
\hline Penyiraman 3 hari sekali & 1.1 & 1.0 \\
\hline
\end{tabular}

Berdasar data pengamatan hasil simulasi dibandingkan dengan data pertanaman di lapang jauh berbeda, hal ini karena pada perlakuan di lapang adanya tumpangsari di lahan petani. Pada pertanaman pak Muhyasin, di mana lahan tidak ada pertanaman tumpangsari dengan tananaman tahunan, kubis tidak dapat dipanen karena terjadi penguapan yang berlebih. Sedangkan pada pertanaman pak Sudirjo, di mana kubis ditanam dibawah pertanaman kopi dan jeruk yang belum berbuah, pertanaman cukup baik. Begitu pula dengan perlakuan mulsa, di mana mulsa sebagai penahan evaporasi dan menjaga kelembaban tanah selain untuk konservasi menyebabkan produksi kubis lebih tinggi dibandingkan dengan tidak memakai mulsa. Pengairan pada musim kemarau juga mempengaruhi pertumbuhan dan produksi kubis, penyiraman setiap hari tanpa mulsa masih memproduksi kubis lebih rendah dibandingkan pertanaman tanpa mulsa dengan penyiraman tiga hari sekali. Sehingga dapat disimpulkan bahwa petani atau pengguna teknologi, bila ingin menanam kubis pada musim kemarau memerlukan modifikasi iklim mikro yaitu pemakaian mulsa dan pengairan tiga hari sekali.

Dari hasil penelitian FAO, produksi kubis yang optimal pada saat kekurangan air hujan adalah $0.5-0.7 \mathrm{~kg} /$ tanaman dan pada saat kondisi air cukup sekitar $1-1.7 \mathrm{~kg} /$ tanaman. Dari perbandingan hasil dilapangan dengan hasil penelitian $\mathrm{FAO}$, terlihat bahwa hasil produksi kubis yang ditanam 18 September 2006 sampai 29 November 2008, di Temanggung merupakan produksi yang cukup baik. 


\section{KESIMPULAN}

1. Adanya introduksi irigasi (penyiraman) dan pemakaian mulsa pada tanaman kubis yang ditanam pada musim kemarau (18 September 2006) kehilangan produksi tidak mencapai $20 \%$, bahkan produksi di Canggal tersebut tidak berbeda dengan hasil produksi penelitian FAO yaitu antara $1-1.7 \mathrm{~kg} /$ tanaman.

2. Pengairan pada musim kemarau mempengaruhi pertumbuhan dan produksi kubis, penyiraman setiap hari tanpa mulsa memproduksi kubis lebih rendah dibandingkan pertanaman tanpa mulsa dengan penyiraman tiga hari sekali.

\section{DAFTAR PUSTAKA}

Arsyad, S. 2000. Konservasi Tanah dan Air. Serial Pustaka IPB Press. 290p

Fagi, AM., Las I., Pane H., Abdulrachman S., Widiarta IN., Baehaki dan Nugraha US., 2002. Anomali Iklim dan Produksi Padi; Srategi dan Antisipasi Penanggulangan. Balai Penelitian Tanaman Padi. Badan Penelitian dan Pengembangan Pertanian. Sukamandi. 41p.

Doorenbos $\mathrm{J}$ and Kassam AH. 1979. Yield response to water. FAO ; Irrigation and drainage paper;33. Rome. 193p.

Doorenbos J and Pruitt WO. 1975. Guidelines for Predicting Crop Water Requirements. FAO Irigation and Drainege Paper; 24. Rome. 179p

Estiningtyas W dan Irianto G. 2002. Penggunaan indeks kecukupan air dan kehilangan hasil untuk penentuan saat tanam dan menekan resiko kekeringan tanaman tebu lahan kering; Antisipasi el-nino dan pendayagunaan sumberdaya iklim dan air untuk meningkatkan produksi dan rendemen tebu lahan kering. Balai Penelitian Agroklimat dan Hidrologi. Pusat Penelitian dan Pengembangan Tanah dan Agroklimat. Badan Penelitian dan Pengembangan Pertanian. Depatemen Pertanian. 48-57p.

Norma MS dan Jauhari S. 2008. Penerapan Irigasi Mikro, Tumpangsari dan Mulsa Untuk Mengantisipasi Kehilangan Hasil Cabai Merah Pada Penanaman Di Musim Kemarau. Jurnal Agromet Indonesia. Vol. XXII No 1, Juni 2008. Bogor. 13-20p.

Setiapermas MN, Koesmaryono, Yusmin dan Irianto, G. 2005. Indeks Kecukupan Air Untuk Penetapan Waktu Bera Kedelai di Jawa Tengah. Jurnal Agromet Indonesia. Vol XIX No 2 Desember 2005. 22-31p. 